\title{
Low-Level Laser Irradiation Modulated Viability of Normal and Tumor Human Lymphocytes In Vitro
}

\author{
Hesam Saghaei Bagheri ${ }^{1,2}$, Seyed Hossein Rasta ${ }^{1,2,3,4}$, Seyedeh Momeneh Mohammadi', Ali Akbar Rahim \\ Rahimi $^{5}$, AliAkbar Movassaghpour ${ }^{6}$, Hojjatollah Nozad Charoudeh ${ }^{1}$ \\ ${ }^{1}$ Stem Cell Research Center, Tabriz University of Medical Sciences, Tabriz, Iran \\ 2Department of Medical Physics, Faculty of Medicine, Tabriz University of Medical Sciences, Tabriz, Iran \\ ${ }^{3}$ Department of Medical Bioengineering, Tabriz University of Medical Sciences, Tabriz, Iran \\ ${ }^{4}$ School of Biomedical Sciences, University of Aberdeen, Aberdeen, UK \\ ${ }^{5}$ Department of Medical Biotechnology, Faculty of Advanced Medical Sciences, Tabriz University of Medical Sciences, \\ Tabriz, Iran \\ ${ }^{6}$ Department of Hematology, Tabriz University of Medical Sciences, Tabriz, Iran
}

\section{*Correspondence to Seyed Hossein Rasta, PhD. Department of Medical physics \& Medical Bioengineering, Tabriz University of Medical Sciences, Tabriz 51666, Iran Tel: +98-9370630833 Email: S.h.rasta@abdn.ac.uk; rastah@tbzmed.ac.ir}

Published online March 15 2020

\begin{abstract}
Introduction: Laser radiation is a promising strategy against various malignancies. Recent studies have shown that the application of low-power laser therapy (LPLT) at different doses and exposure times could modulate the growth dynamic of tumor cells. Based on the type of laser, LPLT could potentially trigger cell proliferation, differentiation, and apoptosis in different cell lines.

Methods: In this study, MTT assay was used to monitor the effect of low and high laser intensities on the viability of normal and cancer lymphocytes. The protein levels of Ki-67 (a proliferation marker) and Caspase-3 (an apoptosis factor) were measured in human peripheral mononuclear cells (PBMCs) and the B-lymphoblastic cell line (Nalm-6) using flow cytometry after being-exposed to 630-nm LPLT at low (2, 4,6 , and $\left.10 \mathrm{~J} / \mathrm{cm}^{2}\right)$ and high $\left(15,30,60\right.$, and $120 \mathrm{~J} / \mathrm{cm}^{2}$ ) energy densities in a continuous mode for 48 and 72 hours.

Results: By using higher energy densities, 60 and $120 \mathrm{~J} / \mathrm{cm}^{2}$, a significant decrease was shown in the viability of Nalm-6 cells, which reached 6.6 and $10.1 \%$ after 48 hours compared to the control cells $(P<0.05)$. Notably, Cell exposure to doses 30,60, and $120 \mathrm{~J} / \mathrm{cm}^{2}$ yielded $7.5,12.9$, and 21.6 cell viability reduction after 72 hours. The collected data showed that the high-intensity parameters of LPLT (15 to $120 \mathrm{~J} / \mathrm{cm}^{2}$ ) promoted significant apoptotic changes in the exposed cells coincided with the activation of Caspase-3 compared to the none-treated control cells $(P<0.05)$. The data further showed the stimulation of the Ki-67 factor both in primary PBMCs and the lymphoblastic cell line treated with LPLT at energy densities of 4 and $6 \mathrm{~J} / \mathrm{cm}^{2}(P<0.05)$, indicating enhanced cell proliferation. Similar to Nalm-6 cells, primary PBMCs showed apoptosis after 48 hours of being exposed to doses 60 , and $120 \mathrm{~J} / \mathrm{cm}^{2}$, indicated by increased Caspase-3 levels $(P<0.05)$. As expected, the Nalm-6 cells were resistant to cytotoxic effects of laser irradiation in the first 48 hours $(P>0.05)$ compared to normal PBMCs. The exposure of Nalm-6 cells to low-intensity laser intensities increased a proliferation rate compared to the PBMCs treated with the same doses.

Conclusion: We showed the potency of LPLT in the induction of apoptosis and proliferation in human primary PBMCs and Nalm- 6 cells in a dose and time-dependent manner after 72 hours.

Keywords: Low-power Laser therapy; Leukemia; Peripheral blood mononuclear cells; Proliferation; Apoptosis.
\end{abstract}

\section{Introduction}

Acute lymphoblastic or lymphocytic leukemia (ALL) is typically characterized by the uncontrolled expansion of immature progenitors of lymphocyte lineage. According to statistics, $80 \%$ of affected children and less than $40 \%$ of adults are cured after different modalities. ${ }^{1,2}$ Recent studies have shown that low-power laser therapy (LPLT) could be touted as a promising strategy against various cancer types. ${ }^{3-7}$ Some recent data have shown that LPLT is applicable at different doses or exposure times to inhibit and/or promote cell growth. In addition, the type of radiation, the pulse or continuous wave laser, could also affect the dynamics of target cells. In this regard, low-level laser radiation has the potential for triggering different cellular bioactivities, mainly proliferation, differentiation, and apoptosis. ${ }^{7-9}$ It has been shown that low-level laser therapy stimulates cell metabolism in different cell types such as HeLa cells, Schwann cells, and fibroblasts. ${ }^{10-12}$ Data from in vitro and in vivo experiments showed that LPLT had healing effects on tissues like skin, cartilage, tendons, muscles, and nerves by promoting photoreceptors. ${ }^{13-16}$ These elements have a capacity for absorbing lights

Please cite this article as follows: Saghaei Bagheri H, Rasta SH, Mohammadi SM, Rahimi AKR, Movassaghpour A, Nozad Charoudeh H, et al. Low-level laser irradiation modulated viability of normal and tumor human lymphocytes in vitro. J Lasers Med Sci. 2020;11(2):174180. doi:10.34172/jlms.2020.29. 
and initiating a metabolic cascade reaction inside the mitochondria that is governed by an enzyme, namely cytochrome C oxidase. ${ }^{17}$ In contrast to the beneficial effects of LPLT, the promotion of pro-inflammatory mediators and consequent cell death were also seen after applying distinct doses and laser intensities. ${ }^{18}$ Both stimulatory and inhibitory effects of light radiation are generated by the same photoreceptors inside the cells. ${ }^{18,19}$ For instance, the exposure of human lung adenocarcinoma cells to laser radiation at $120 \mathrm{~J} / \mathrm{cm}^{2}$ induced apoptosis by promoting mitochondrial-Caspase- 3 signaling pathways. ${ }^{6,7} \mathrm{Wu}$ et al proved that LPLT radiation increased the production of reactive oxygen species (ROS) and activated apoptotic factors, notably Bax in multiple cancer cell lines, including ASTC-a-1, HepG2, HeLa, and A549 cells. ${ }^{6,20}$ In this study, we evaluated the proliferation and apoptosis of human primary peripheral mononuclear cells (PBMCs) and B-lymphocytic cell lines (Nalm-6) after being exposed to high and low energy densities of LPLT in an in vitro condition during 48- and 72-hours post-irradiation.

\section{Materials and Methods}

Sampling and Cell Expansion

We purchased the ALL cell line (Nalm-6; NCBI code: CCRF-CEM) from the Iran National Cell Bank (Pasteur Institute, Tehran) and maintained it in an RPMI 1640 medium (Gibco) with 10\% fetal bovine serum (FBS, Gibco) and 1\% Pen-Strep solution (Biosera). Human PBMCs were also isolated from the blood samples of healthy donors using Ficoll-Paque Plus (Ref no: 002041600, Inno-train) and then diluted with an equal volume of phosphate-buffered saline (PBS). The samples were gently overlaid to the same volume of FicollHypaque solution and centrifuged at $400 \mathrm{~g}$ for 40 minutes at $4^{\circ} \mathrm{C}$. After the completion of centrifugation, PBMCs at the interphase between Ficoll-Hypaque and PBS were carefully collected by sterile pipettes and washed twice with PBS. To expand the cells, freshly isolated mononuclear cells were suspended in a culture medium of RPMI-1640 supplemented with 10\% FBS and 1\% PenStrep solution and transferred into Ultra-Low adherent culture plates (Greiner; Germany). The culture plates were maintained at a conventional atmosphere with 5\% $\mathrm{CO}_{2}$ and $90 \%$ humidity. The cell media were replaced every 3-4 days.

\section{Laser Radiation Procedure}

We used continuous-wave red laser light using a GaAlAs diode laser (Model: Mustang 2000+, Russia) at a wavelength of $630 \mathrm{~nm}$. The output power was adjusted to $34 \pm 2 \mathrm{~mW}$ with the acupuncture nuzzle of $6.6 \mathrm{~mm}$ in diameter. The Gaussian laser-beam feature was applied to all cells. For laser treatment, $5 \times 10^{5}$ cells from the primary cells and Nalm- 6 line were seeded separately in Ultra-Low adherent 96 well plates (Greiner; Germany). The laser beam area was $0.33 \mathrm{~cm}^{2}$ and the power densities reached $99.43 \mathrm{~mW} / \mathrm{cm}^{2}$ at energy densities of $2,4,6,10$, $15,30,60$, and $120 \mathrm{~J} / \mathrm{cm}^{2}$. Radiation time was adjusted to a range of 20 to 1200 seconds for different time periods. The cells were exposed to low-level laser radiation for two consecutive days and subjected to MTT and flow cytometry analyses.

\section{MTT Assay}

We performed a conventional survival assay, namely MTT analysis, in order to assess the dose-dependent proliferative and cytotoxic effects of LPLT. MTT analysis was performed using the 3-[4, 5-dimethylthiazol-2-yl] $-2,5$ diphenyltetrazolium bromide (MTT, Sigma). The plates were incubated at $37^{\circ} \mathrm{C}$ with $5 \% \mathrm{CO}_{2}$ for 4 hours. During this procedure, vital cells absorbed MTT and produced formazan crystals. After 4 hours, we added 100 $\mu \mathrm{L}$ solubilizing solutions, $10 \%$ sodium dodecyl sulfate in $0.01 \mathrm{M} \mathrm{HCl}$. Then, the plates were placed on the shaker and agitated for 20 minutes to dissolve the formazan crystals. The final absorbance was measured at different wavelengths ranging from $570 \mathrm{~nm}$ to $630 \mathrm{~nm}$. Finally, cell viability was calculated based on the percentage of the time-matched control group.

Antibodies and Flow Cytometry Analysis

Following the irradiation protocol, the treated cells were analyzed by flow cytometry to evaluate the protein levels of Caspase 3 and Ki-67. The cells were collected and washed several times using PBS and then were permeabilized by using the Cytofix/Cytoperm solution (Cat No: 51$6896 \mathrm{KC}, \mathrm{BD}$ Biosciences) at $4^{\circ} \mathrm{C}$ for 20 minutes. The washing procedure was again repeated by using the Perm/ Wash solution (Cat No: 51-6897KC, BD Biosciences) followed by incubating the cells in a $20 \mu \mathrm{L}$ PE-conjugated mouse anti-human Caspase 3 antibody (Cat No: 550914 BD Pharmingen active caspase- 3 apoptosis kit) and a $5 \mu \mathrm{L}$ PE-conjugated mouse anti-human Ki-67 antibody (Cat No: 12-5699-42; eBioscience, Inc.; USA) for 20 minutes at room temperature. After being washed twice with PBS, the cells were analyzed by the BD FACSCalibur system (BD Bioscience) and the collected data were processed by using FlowJo software ver. X.0.7.

\section{Statistical Analysis}

The data are expressed as mean \pm SD. The statistical analysis was done by using one-way ANOVA and the Tukey's HSD test. $P<0.05$ was considered statistically significant.

\section{Results}

The Effects of LPLT on the Viability of PBMCs and Nalm6 Cells

We used the MTT assay to determine the rate of cell viability in PBMCs and Nalm-6 after exposure to different laser intensities. Cell irradiation at energy densities of 4 and $6 \mathrm{~J} / \mathrm{cm}^{2}$, but not $2 \mathrm{~J} / \mathrm{cm}^{2}$, was shown to stimulate 
PBMCs proliferation after 48 hours, reaching 11.6 and $9.9 \%$ respectively compared to the control group $(P<0.05$; Figure 1A). These values were 8.7, 20.9, and $30.4 \%$ after 72 hours at energy densities of 2, 4 and $6 \mathrm{~J} /$ $\mathrm{cm}^{2}(P<0.05$; Figure 1A). The use of the same protocol at energy densities of 2, 4, 6 and $10 \mathrm{~J} / \mathrm{cm}^{2}$ stimulated Nalm6 cell proliferation and yielded similar results $(7.4,14.9$, 13.6 , and $7.9 \%$ respectively) compared to the non-treated control cells $(P<0.05$; Figure 1B). Based on the data from the MTT panel, cell exposure to different laser intensities ranging from 2 to $10 \mathrm{~J} / \mathrm{cm}^{2}$ increased the viability of Nalm-6 cells to $11.6,49.4,24.9$ and $10.6 \%$ respectively after 72 hours $(P<0.05$; Figure $1 \mathrm{~B})$.

The viability of PBMCs significantly decreased in groups 60 and $120 \mathrm{~J} / \mathrm{cm}^{2}$ (8.4 and 13.2\%) after 48 hours compared to the control group $(P<0.05$; Figure $1 \mathrm{~A})$. Higher cytotoxic effects were observed in these cells at energy densities of $15,30,60$ and $120 \mathrm{~J} / \mathrm{cm}^{2} 72$ hours postirradiation $(8.8 \%, 12.8 \%, 18.4 \%$ and $26.2 \%$ respectively) compared to the control cells. Similar to these results, a significant decrease (6.6\% and $10.1 \%$ respectively) in the survival of Nalm- 6 cell lines was observable at energy densities of 60 and $120 \mathrm{~J} / \mathrm{cm}^{2}$ after 48 hours compared to the control Nalm- 6 cells $(P<0.05$; Figure 1B). As expected, Nalm-6 treatment with the doses of $30,60,120 \mathrm{~J} / \mathrm{cm}^{2}$ contributed to $7.5,12.9$, and $21.5 \%$ cell reduction after 72 hours $(P<0.05$; Figure $1 \mathrm{~B})$. Based on our results, it seems that the primary cells are more sensitive to stimulatory and inhibitory effects of laser irradiation at distinct doses in comparison with the immortalized cell line, Nalm-6.

The Induction of Apoptosis at High- Fluence LPLT

Following cell exposure to higher laser intensities at the range of 30,60 and $120 \mathrm{~J} / \mathrm{cm}^{2}$, we evaluated apoptosis by monitoring the intracellular levels of Caspase-3 (a marker of apoptosis) via flow cytometry analysis. 48 hours after irradiation, Caspase- 3 positive PBMCs were $1.5 \%, 2.5 \%$, and $2.9 \%$ and the cells from group 60 and $120 \mathrm{~J} / \mathrm{cm}^{2}$ showed significant changes compared to the control PBMCs $(P<0.05$; Figure $2 \mathrm{~A}-\mathrm{B})$. These values reached significant levels $(14.9 \%, 55.6 \%$, and $60.7 \%)$ after 72 hours compared with the control group $(P<0.05$; Figure 2A-B). In contrast to PBMCs, the treatment of Nalm- 6 with the same doses caused a non-statistically difference in the percent of the Caspase- 3 positive cells $(1.1 \%, 1.6 \%$, and $1.9 \%)$ after 48 hours. It seems that these values increased to significant levels $(3.9 \%, 6.3 \%$, and $15.8 \%)$ after 72 hours in the cells from 30, 60 and $120 \mathrm{~J} /$ $\mathrm{cm}^{2}$ groups $(P<0.05$; Figure $2 \mathrm{C}-\mathrm{D})$. It was shown that the induction of apoptosis and Caspase-3 activity correlated with the doses and time periods. In addition, these data showed that tumor cells were more resistant to similar energy intensities than normal PBMCs. In addition, the cytotoxic and promotive effects of laser irradiation were determined by time.
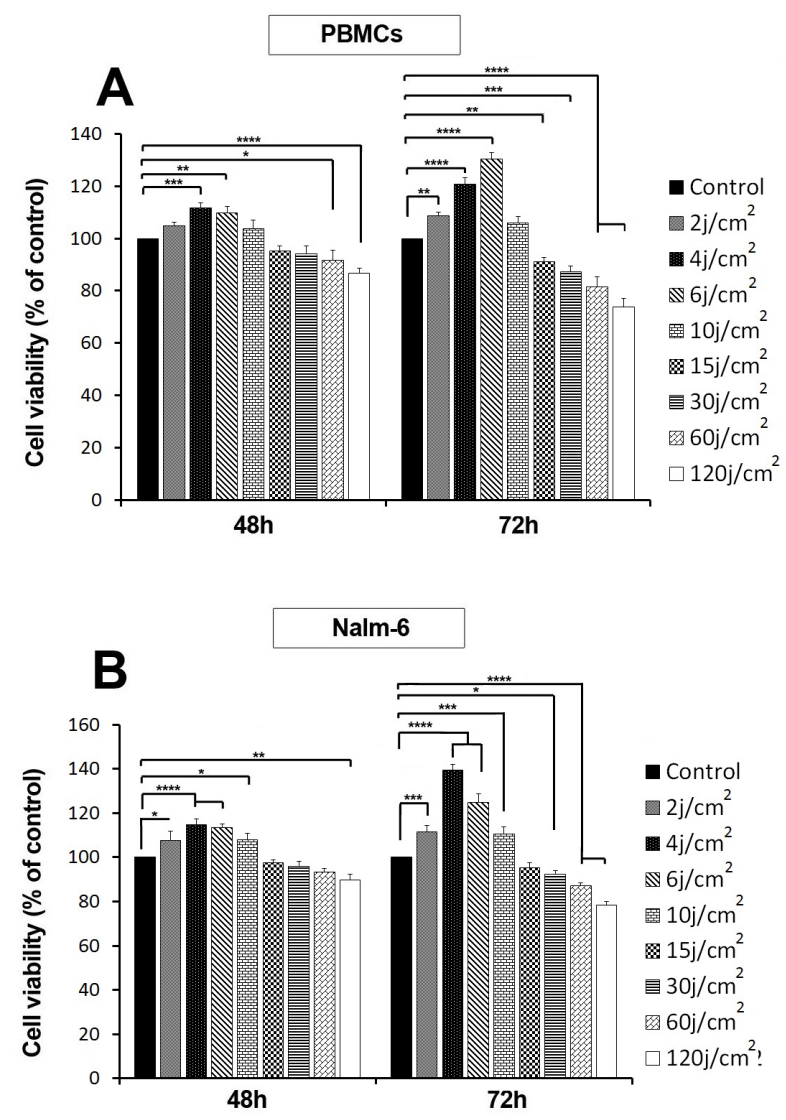

Figure 1. Measuring PBMCs and Nalm-6 Survival Rate by MTT Assay After the High- Intensity and Low-Intensity Laser Radiation (A-B). Data are expressed as mean $\pm S D(n=6)$. Values correspond to mean \pm SD. The cell viability of both cell types in the LLLI-treated group showed a significant difference compared with the control group (non-irradiated). Differences between the control and treated groups are significant at ${ }^{*} P<0.05$, ${ }^{* *} P<0.01,{ }^{* * *} P<0.001$ and ${ }^{* * * *} P<0.0001$ (ANOVA and the Tukey HSD test).

Cell Proliferation Stimulated by LPLT at Low Energy Density Doses

The analysis of the data from flow cytometry analysis showed that there was a significant increase in the percent of Ki-67 positive PBMCs (23.7, and 15.6\%) 48 hours after being exposed to doses 4 and $6 \mathrm{~J} / \mathrm{cm}^{2}(P<0.05$; Figure 3AB). 72 hours after irradiation, we found an increase in the proliferation of Ki-67 PBMCs (26\% and 35.4\%) compared to the non-treated control group. In Nalm-6 cells, the application of doses 4 and $6 \mathrm{~J} / \mathrm{cm}^{2}$ caused enhanced cell proliferation $(7.6 \%$ and $10.2 \%)$ in comparison with the control group $(P<0.05$; Figure $3 \mathrm{C}-\mathrm{D})$. By the time, the percent of Ki-67 positive Nalm-6 cells reached 6.5 and $10.2 \%$ compared to the control group $(P<0.05$; Figure $3 \mathrm{C}-\mathrm{D})$. These data stand for a fact that the use of lower LPLT doses could increase the rate of cell proliferation by time in either normal or cancer cells.

\section{Discussion}

In favor of the clinical approach, red or infrared laser diodes at a range of 10 to $100 \mathrm{~mW}$ have routinely been used for therapeutic approaches. ${ }^{21}$ However, such laser radiation 


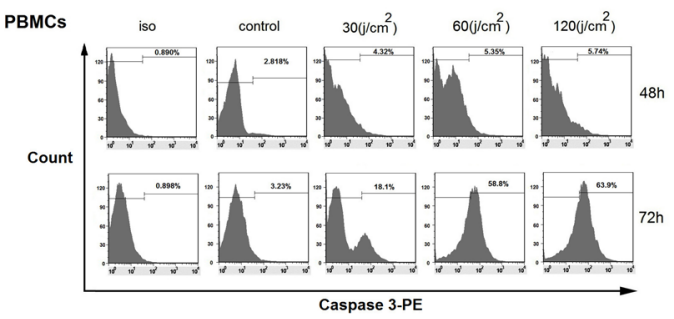

C

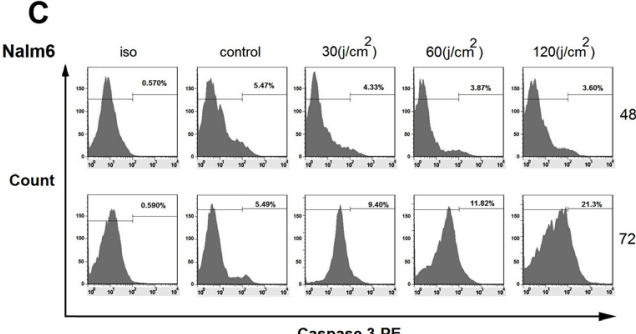

B

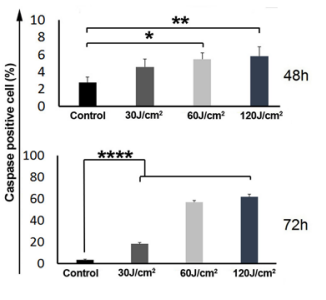

D

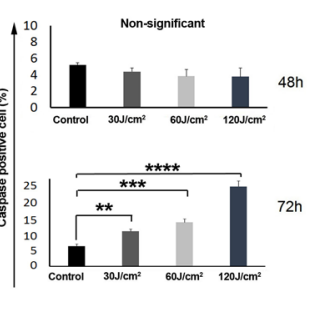

Figure 2. Measuring Apoptosis (Caspase-3 Levels) in Laser-Irradiated Cells by Flow Cytometry Analysis (A-D). Flow cytometry analysis revealed the induction of Caspase-3 in PBMCs (A-B) Nalm-6 cells (C-D) after exposure to higher laser doses, 30, 60 and 120 J/cm², analyzed after 48 and 72 hours. Data are expressed as mean $\pm \mathrm{SD}(n=6)$. Differences between the control and treated groups are significant at ${ }^{*} P<0.05,{ }^{* *} P<0.01,{ }^{* * *} P<0.001$ and ${ }^{* * * *} P<0.0001(\mathrm{ANOVA}$ and the Tukey HSD test)

A

B
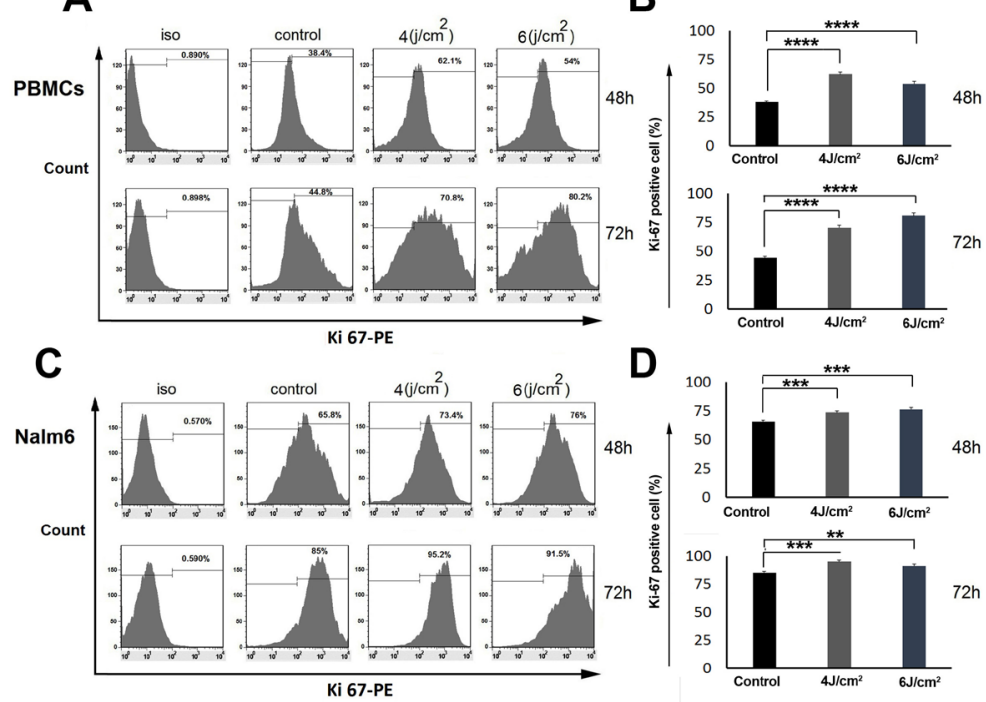

Figure 3. Flow Cytometric Analysis of Cell Proliferation By Monitoring Ki-67 in PBMCs (A-B) and Nalm-6 Cells (C-D) Exposed to Lower Laser Energy Intensities After 48 and 72 Hours. Data are expressed as mean \pm SD $(n=6)$. Differences between the control and treated groups are significant at ${ }^{* *} P<0.01$, ${ }^{* * *} P<0.001$ and ${ }^{* * * *} P<0.0001$ (ANOVA and the Tukey HSD test).

as an alternative clinical modality for the inhibition of cancers is still under investigation. Notably, results have shown the inhibitory effects of laser irradiation on cancer cell proliferation. ${ }^{22}$ In this regard, Wang et al have shown that human lung adenocarcinoma cells (ASTC-a-1) enter apoptosis 6 hours after exposure to high-intensity LPLT $\left(60\right.$ and $\left.120 \mathrm{~J} / \mathrm{cm}^{2}\right) .5$ They also noted the efficiency of Caspase- 3 induction by using the fluorescence resonance energy transfer method..$^{5}$ These modalities contributed to the superior effect of phototherapies such as highintensity LPLT on human cancer cells. It was shown that LPLT at higher energy intensities was able to generate large amounts of singlet oxygen that in turn initiated the oxidation of a large variety of biological molecules in DNA damage and apoptosis initiation. ${ }^{23}$ Also, Huang and co-workers confirmed the involvement of the Akt/ GSK3 $\beta$ pathway and the expression of Bax in cells soon after cell exposure to LPLT. ${ }^{24,25}$ In laser-irradiated cells, 
viability diminished by the abrogation of Nox4 and surviving activities. ${ }^{26}$ Another possible mechanism that makes the cells sensitive to irradiation correlates with the reticulum endoplasmic stress and the induction of autophagy modulators such as activating transcription factor- $4 .{ }^{27,28}$ It was recently shown that the treatment of human ovarian cancer and endothelial lineage with laser irradiation at high energy intensities was able to bring about oncostatic effects by the simultaneous expression of heat shock protein 70 after 72 hours. ${ }^{29}$ In addition to different cytotoxic properties, various mechanisms for the mitogenic effects of LPLT have also been suggested at specific intensities. ${ }^{30,31}$ Therefore, it is reasonable to claim that the cell survival rate is dependently related to the irradiation intensity and the time period.

Our results showed that Ki-67 expression was stimulated in both primary PBMCs and lymphoblastic cell lines, especially at energy densities of 4 and $6 \mathrm{~J} / \mathrm{cm}^{2}$. In line with our results, Prabhu et al have also shown that the Ki-67 and proliferating cell nuclear antigen (PCNA) expression increased by laser exposure in rat models for healing. ${ }^{32,33}$ They have also claimed that a single exposure of cells to $2 \mathrm{~J} / \mathrm{cm}^{2}$ was able to increase cell proliferation of basal cells, whereas the application of a higher dose at $10 \mathrm{~J} / \mathrm{cm}^{2}$ inhibited the expression of Ki-67 and PCNA after 10 days. In this regard, Taniguchi et al showed that the upstream signaling cascade of PCNA and Ki-67 in synovial fibroblasts played a role in the activation of p15 during photo bio-stimulation. ${ }^{34}$ In parallel, the application of $\mathrm{He}-\mathrm{Ne}$ laser radiation (632.8 $\mathrm{nm}$ ) increased the translational expression of cyclin D1 in mouse satellite cells. ${ }^{35,36}$ Other experiments revealed that photobiomodulation stimulated mitochondrial enzymes in the respiratory chain, affecting electron transfer and increased the intracellular calcium content. These changes, in turn, enhance cell proliferation. ${ }^{17,37,38}$ It is believed that the mitochondrial cytochrome $\mathrm{C}$ oxidase could absorb red to near-infrared light, which is one of the respiratory chain components, resulting in the generation of ROS and adenosine triphosphate (ATP). ${ }^{38}$

\section{Conclusion}

In conclusion, we showed that both apoptosis and proliferation could be induced in the primary PBMCs and the B-lymphocyte cell line (Nalm-6) by LPLT at different energy intensities and time periods. We also confirmed that the bio-stimulatory effect of LPLT on PBMCs and Nalm- 6 cells was dose- and time-dependent and in doses of 2, 4, 6 and $10 \mathrm{~J} / \mathrm{cm}^{2}$ could increase the cell proliferation rate while higher energy rates ranging from 15 to $120 \mathrm{~J} /$ $\mathrm{cm}^{2}$ were able to stimulate cell apoptosis. We concluded that special doses of LPL radiation must be selected for therapeutic goals and achieving a desirable modulatory effect on the proliferation and apoptosis activities of cancer cells.

\section{Ethical Considerations}

All procedures performed in this study involving human participants were in accordance with the ethical standards of the research committee of Tabriz University of Medical Sciences (ethical code: TBZMED.REC.1394.585) and with the 1964 Helsinki declaration and its later amendments. Informed consent was obtained from all individual participants included in the study.

\section{Conflict of Interests}

The authors declare no conflict of interest.

\section{Funding}

This study was financially supported by a grant from the Stem Cell Research Center of Tabriz University of Medical Sciences.

\section{Acknowledgment}

We thank the experts in the Stem Cell Research Center of Tabriz University of Medical Sciences for their kind support.

\section{References}

1. Hunger SP, Mullighan CG. Acute lymphoblastic leukemia in children. N Engl J Med. 2015;373(16):1541-52. doi: 10.1056/NEJMra1400972.

2. Soulier J, Cortes J. Introduction to the review series on acute lymphoblastic leukemia. Blood. 2015; 125(26):39656. doi: 10.1182/blood-2015-05-635300.

3. Friedmann H, Lubart R. Towards an explanation of visible and infrared laser induced stimulation and damage of cell cultures. Laser Ther. 1992;4(1):39-42. doi: 10.5978/ islsm.92-OR-03.

4. Kujawa J, Zavodnik IB, Lapshina A, Labieniec M, Bryszewska M. Cell survival, DNA, and protein damage in B14 cells under low-intensity near-infrared $(810 \mathrm{~nm})$ laser irradiation. Photomed Laser Surg. 2004;22(6):504-8. doi: 10.1089/pho.2004.22.504.

5. Wang F, Chen TS, Xing D, Wang JJ, Wu YXJ. Measuring dynamics of caspase- 3 activity in living cells using FRET technique during apoptosis induced by high fluence lowpower laser irradiation. Lasers Surg Med. 2005;36(1):2-7. doi: $10.1002 / \mathrm{lsm} .20130$.

6. Wu S, Xing D, Gao X, Chen WR. High fluence low-power laser irradiation induces mitochondrial permeability transition mediated by reactive oxygen species. J Cell Physiol. 2009;218(3):603-11. doi: 10.1002/jcp.21636.

7. Maldaner DR, Azzolin VF, Barbisan F, Mastela MH, Teixeira CF, Dihel A, et al. In vitro effect of low-level laser therapy on the proliferative, apoptosis modulation, and oxi-inflammatory markers of premature-senescent hydrogen peroxide-induced dermal fibroblasts. Lasers Med Sci. 2019;34(7):1333-1343. doi: 10.1007/s10103-01902728-1.

8. Bagheri HS, Mousavi M, Rezabakhsh A, Rezaie J, Rasta $\mathrm{SH}$, Nourazarian A, et al. Low-level laser irradiation at a high power intensity increased human endothelial cell exosome secretion via Wnt signaling. Lasers Med Sci. 
2018;33(5):1131-45. doi: 10.1007/s10103-018-2495-8.

9. Zamani ARN, Mashayekhi MR, Jadid MFS, Faridvand Y, Tajalli H, Rahbarghazi R. Photo-modulation of zinc phthalocyanine-treated breast cancer cell line ZR-75-1 inhibited the normal tumor activity in vitro. Lasers Med Sci. 2018;33(9):1969-78. doi: 10.1007/s10103-018-2563-0.

10. Djavid GE, Goliaie B, Nikoofar A. Analysis of radiomodulatory effect of low-level laser irradiation by clonogenic survival assay. Photomed Laser Surg. 2015;33(9):452-9. doi: 10.1089/pho.2015.3893.

11. Yang CC, Wang J, Chen SC, Hsieh YL. Synergistic effects of low-level laser and mesenchymal stem cells on functional recovery in rats with crushed sciatic nerves. J Tissue Eng Regen Med. 2016;10(2):120-31. doi: 10.1002/term.1714.

12. Lee Y, Kim H, Hong N, Ahn JC, Kang HW. Combined treatment of low-level laser therapy and phloroglucinol for inhibition of fibrosis. Lasers Surg Med. 2019. doi: 10.1002/ $1 \mathrm{sm} .23131$.

13. Bibikova A, Oron U. Promotion of muscle regeneration in the toad (Bufo viridis) gastrocnemius muscle by lowenergy laser irradiation. Anat Rec. 1993;235(3):374-80. doi: 10.1002/ar.1092350306.

14. Nicolopoulos N, Cavadias C, Karameris A, Dyson M, Tsourouktsoglou A, Kondoyannis P. The use of laser surgery in subtotal meniscectomy and the effect of low-level laser therapy on the healing potential of rabbit meniscus: an experimental study. Lasers Med Sci. 1996;11(2):109-15. doi: 10.1007/BF02133207.

15. Freeman, C. The Effects of Pre and Post Exercise Low-Level Laser Therapy on Biochemical Markers of Skeletal Muscle Fatigue in Equines [dissertation]. Arkansas: University of Arkansas: 2019.

16. Dias FJ, Fazan VPS, Cury DP, de Almeida SRY, Borie E, Fuentes R, et al. Growth factors expression and ultrastructural morphology after application of low-level laser and natural latex protein on a sciatic nerve crushtype injury. PLoS One. 2019;14(1):e0210211. doi: 10.1371/ journal.pone.0210211.

17. Lima PL, Pereira CV, Nissanka N, Arguello T, Gavini G, Maranduba CM, et al. Photobiomodulation enhancement of cell proliferation at $660 \mathrm{~nm}$ does not require cytochrome c oxidase. J Photochem Photobiol B. 2019;194:71-5. doi: 10.1016/j.jphotobiol.2019.03.015.

18. Alves AC, de Paula Vieira R, Leal-Junior ECP, dos Santos SA, Ligeiro AP, Albertini R, et al. Effect of low-level laser therapy on the expression of inflammatory mediators and on neutrophils and macrophages in acute joint inflammation. Arthritis Res Ther. 2013;15(5):R116. doi: $10.1186 / a r 4296$.

19. Moriyama Y, Nguyen J, Akens M, Moriyama EH, Lilge L. In vivo effects of low level laser therapy on inducible nitric oxide synthase. Lasers Surg Med. 2009;41(3):227-31. doi: 10.1002/lsm.20745.

20. Zhao MX, Wen JL, Wang L, Wang XP, Chen TS. Intracellular catalase activity instead of glutathione level dominates the resistance of cells to reactive oxygen species. Cell Stress Chaperones. 2019;24(3):609-19. doi: 10.1007/s12192-01900993-1.

21. Ottaviani G, Martinelli V, Rupel K, Caronni N, Naseem $\mathrm{A}$, Zandonà $\mathrm{L}$, et al. Laser therapy inhibits tumor growth in mice by promoting immune surveillance and vessel normalization. EBioMedicine. 2016;11:165-72. doi: 10.1016/j.ebiom.2016.07.028.

22. Frigo L, Luppi JS, Favero GM, Maria DA, Penna SC, Bjordal $\mathrm{JM}$, et al. The effect of low-level laser irradiation (In-GaAl-AsP- $660 \mathrm{~nm}$ ) on melanoma in vitro and in vivo. BMC Cancer. 2009;9:404. doi: 10.1186/1471-2407-9-404.

23. Morkunas V, Urbonaite G, Gabryte-Butkiene E, Sobutas $S$, Vengris $M$, Danielius R, et al. DNA-damaging effect of different wavelength (206 and $257 \mathrm{~nm}$ ) femtosecond laser pulses. Photobiomodul Photomed Laser Surg. 2019;37(4):254-61. doi: 10.1089/photob.2018.4540.

24. Huang L, Wu S, Xing D. High fluence low-power laser irradiation induces apoptosis via inactivation of Akt/ GSK3 $\beta$ signaling pathway. J Cell Physiol. 2011;226(3):588601. doi: $10.1002 /$ jcp. 22367 .

25. Jere SW, Houreld NN, Abrahamse H. Role of the PI3K/ AKT (mTOR and GSK3 $\beta$ ) signalling pathway and photobiomodulation in diabetic wound healing. Cytokine Growth Factor Rev. 2019;50:52-59. doi: 10.1016/j. cytogfr.2019.03.001.

26. Chu J, Wu S, Xing. Survivin mediates self-protection through ROS/cdc25c/CDK1 signaling pathway during tumor cell apoptosis induced by high fluence low-power laser irradiation. Cancer Lett. 2010; 297(2):207-19. doi: 10.1016/j.canlet.2010.05.013.

27. Carnevalli CM, Soares CP, Zângaro RA, Pinheiro AL, Silva NS. Laser light prevents apoptosis on Cho K-1 cell line. J Clin Laser Med Surg. 2003;21(4):193-6. doi: 10.1089/104454703768247756.

28. Khan I, Tang E, Arany P. Molecular pathway of nearinfrared laser phototoxicity involves ATF-4 orchestrated ER stress. Sci Rep. 2015;5:10581. doi: 10.1038/srep10581.

29. Akbarzadeh M, Nouri M, Banekohal MV, Cheraghi O, Tajalli H, Movassaghpour A, et al. Effects of combination of melatonin and laser irradiation on ovarian cancer cells and endothelial lineage viability. Lasers Med Sci. 2016;31(8):1565-72. doi: 10.1007/s10103-016-2016-6.

30. Tunç H, Islam A, Kabadayı H, Vatansever HS, Yilmaz HG. Evaluation of low-level diode laser irradiation and various irrigant solutions on the biological response of stem cells from exfoliated deciduous teeth. J Photochem Photobiol B. 2019;191:156-63. doi: 10.1016/j.jphotobiol.2019.01.001.

31. Andreo L, Mesquita-Ferrari RA, Ribeiro BG, Benitte A, de Fátima Nogueira T, França CM, et al. Effects of myogenic precursor cells $(\mathrm{C} 2 \mathrm{C} 12)$ transplantation and low-level laser therapy on muscle repair. Lasers Surg Med. 2018. doi: 10.1002/lsm.22798.

32. Prabhu V, Rao BSS, Mahato KK. Low power laser irradiation stimulates cell proliferation via proliferating cell nuclear antigen and Ki-67 expression during tissue repair. In: Hamblin MR, Carroll JD, Arany P, editors. Proceedigs of the SPIE BIOS 2015: Mechanisms for Low-Light Therapy X: International Society for Optics and Photonics, San Francisco, California: SPIE Digital Library; 2015. doi: 10.1117/12.2077747

33. Nassar EA, Fouda AM, Hassan KS. Influence of lowlevel laser (LLL) on interleukin 6 (IL-6) levels in gingival crevicular fluid (GCF) during orthodontic tooth movement of periodontally affected rabbits. Int Orthod. 
2019;17(2):227-34. doi: 10.1016/j.ortho.2019.03.004.

34. Taniguchi D, Dai P, Hojo T, Yamaoka Y, Kubo T, Takamatsu T. Low-energy laser irradiation promotes synovial fibroblast proliferation by modulating p15 subcellular localization. Lasers Surg Med. 2009;41(3):232-9. doi: 10.1002/lsm.20750.

35. Gao X, Xing D. Molecular mechanisms of cell proliferation induced by low power laser irradiation. J Biomed Sci. 2009;16(1):4. doi: 10.1186/1423-0127-16-4.

36. Fonda-Pascual P, Alegre-Sánchez A, Harto-Castaño A, Moreno-Arrones OM, Pérez-García B, González-Morales ML, et al. Low-level light-assisted photodynamic therapy using a wearable cap-like device for the treatment of actinic keratosis of the scalp. Photodiagnosis Photodyn Ther. 2019;25:136-41. doi: 10.1016/j.pdpdt.2018.11.018.

37. Paschalidou M, Athanasiadou E, Arapostathis K, Kotsanos N, Koidis PT, Bakopoulou A, et al. Biological effects of lowlevel laser irradiation (LLLI) on stem cells from human exfoliated deciduous teeth (SHED). Clin Oral Investig. 2019; 24(1): 167-80. doi: 10.1007/s00784-019-02874-4.

38. Tsuka Y, Kunimatsu R, Gunji H, Nakajima K, Kimura A, Hiraki T, et al. Effects of Nd: YAG low-level laser irradiation on cultured human osteoblasts migration and ATP production: in vitro study. Lasers Med Sci. 2018;34(1):5560. doi: 10.1007/s10103-018-2586-6. 